\title{
Effect of Deep Sea Pressures on the Corrosion Behavior of X65 Steel in the Artificial Seawater
}

\author{
Qiu-Shi Li ${ }^{1}$. Shun-Zhong Luo ${ }^{1}$ Xu-Teng Xing ${ }^{1} \cdot$ Jing Yuan $^{1,2} \cdot$ Xin Liu $^{1} \cdot$ Ji-Hui Wang ${ }^{1} \cdot$ Wen-Bin Hu ${ }^{1}$
}

Received: 25 June 2018 / Revised: 22 October 2018 / Published online: 6 December 2018

(c) The Chinese Society for Metals (CSM) and Springer-Verlag GmbH Germany, part of Springer Nature 2018

\begin{abstract}
The corrosion behaviors of X65 steel in the artificial seawater at different hydrostatic pressures are investigated by potentiodynamic polarization measurements, electrochemical impedance spectroscopy measurements and weight loss measurements. The corroded morphologies and the corrosion products are also investigated by scanning electron microscopy, X-ray diffraction analysis and Raman analysis. The results show that the corrosion current increases as the hydrostatic pressure increases. The charge transfer resistance decreases as the hydrostatic pressure increases. The corrosion products are mainly composed of $\gamma$ - $\mathrm{FeOOH}$ and $\mathrm{Fe}_{3} \mathrm{O}_{4}$ at the atmospheric pressure, while the main components are $\gamma$ - $\mathrm{FeOOH}, \mathrm{Fe}_{3} \mathrm{O}_{4}$, and $\gamma$ - $\mathrm{Fe}_{2} \mathrm{O}_{3}$ at the high pressure. The hydrostatic pressure accelerates the corrosion of X65 steel due to its effect on the chemical and physical properties of corrosion products, including the promoted reduction of $\gamma$-FeOOH and the wider and deeper cracks on the corrosion products layer.
\end{abstract}

Keywords X65 steel $\cdot$ Deep sea pressures $\cdot$ Electrochemical measurements $\cdot$ Corrosion

\section{Introduction}

The marine industry has been developed rapidly since the twentieth century. Remarkable successes have been achieved in the offshore oil and gas exploration and transportation [1]. According to statistics, offshore oil reserves of about 100 billion tons, accounting for $34 \%$ of global oil resources. In recent years, the demand for energy in the world has been increasing. With the increasing exploration, oil and gas reserves in shallow seas are gradually depleted. The offshore oil and gas development has shifted from the shallow sea to the deep sea. The deep-sea environment is different from the shallow-sea environment. Materials in the deep sea will

Available online at http://link.springer.com/journal/40195

Ji-Hui Wang

jhwang@tju.edu.cn

Qiu-Shi Li

qsli@tju.edu.cn

1 Tianjin Key Laboratory of Composite and Functional Materials, School of Materials Science and Engineering, Tianjin University, Tianjin 300072, China

2 College of Physics Electronic Information Engineering, Qinghai University for Nationalities, Xining 810007, China face more severe challenges than in the shallow sea [2]. The submarine pipeline is the main structure of offshore oil and gas transportation. The pipeline is difficult and expensive to repair in the deep sea, once the corrosion failures occur on it. Due to the severe corrosion threats, the corrosion problem of deep-sea pipelines has become one of the worldwide focuses.

Various researches have been reported to study the influences of the deep-sea environment on the corrosion behavior of pipelines. The influence factors include the hydrostatic pressure (HP), dissolved oxygen content, salinity, temperature, and $\mathrm{pH}[3-5]$. The influence mechanisms of the factors have been investigated in detail except the HP. The HP is directly related to the water depth. The corrosion of pipelines in the deep-sea environment with the high HP has been studied since the 1960s. The researchers from America, India, and China have reported the in situ performance of materials in the sea up to a depth of $5100 \mathrm{~m}$ [6-8]. The experiments obtained the most realistic corrosion data of the materials in the deep sea. Recently, Canepa et al. [9] have reported the corrosion of aluminum, copper, and iron metals and their alloys in the deep-sea environment through an in situ exposure. Corrosion rates of different materials are determined by the weight loss method and the morphology analysis. The results show that in the deep-sea environment where the exposure is carried out, 
the stainless steel is the most resistant to corrosion, while the corrosion of copper-nickel alloy is the most serious.

Although the in situ exposure test can obtain the most realistic corrosion information of materials in the deep sea, the test has the disadvantages of high cost, long cycle, and difficult implementation. In order to avoid these problems, laboratory experiments are also performed to investigate the corrosion behavior of metals affected by HPs. Beccaria et al. [10-12] have reported the effect of high HPs on the corrosion of nickel, stainless steels, aluminum alloys in the sea water. The results reveal that the corrosion of these metals increases as the HP increases, due to the enhanced effect on localized corrosion. Zhang et al. [13] have also reported the increased pitting susceptibility of Fe-20Cr alloy at the high HP. In a further study, Zhang et al. [14] have found that the HP deteriorates the passive films of 316L stainless steel by reducing the pitting incubation time and the amount of $\mathrm{Fe}_{2} \mathrm{O}_{3}$ and $\mathrm{Cr}(\mathrm{OH})_{3}$ oxides. Though these studies provide deep analysis on the corrosion behavior affected by HPs, the works focus on passive metals. However, most of the metals applied for submarine pipelines are active metals, such as X65 steel and X70 steel. The corrosion behavior of active metals is different from that of passive metals. Recently, Yang et al. have reported that the HP can promote the corrosion of X70 steel for the whole immersion period. The results reveal that in the initial stage of corrosion, the HP accelerates corrosion by promoting the pitting initiation and propagation. In the later stages of corrosion, the HP accelerates corrosion by promoting the transport and adsorption of chloride ions in the corrosion product layer [15]. The influence and mechanisms of the HP on the corrosion behaviors of pipeline steels are worthy of further study.

The objective of this work is to explore the effect of HPs on the corrosion behavior of X65 steel in the artificial seawater. The corrosion behavior of $\mathrm{X} 65$ steel is investigated at different HPs. Electrochemical impedance measurements and potentiodynamic polarization measurements are taken at different HPs. The corroded morphologies of X65 steel at different HPs are observed using the scanning electron microscope. The corrosion products formed at different pressures are analyzed by the X-ray diffraction and the laser Raman spectrometer. The influence mechanism of the HP on the corrosion behavior of X65 steel is developed based on the comprehensive analysis of electrochemical measurements, weight loss, and surface characterizations.

Table 1 Chemical compositions of X65 steel (wt\%)

\section{Experimental}

\subsection{Materials and Electrolytes}

The chemical compositions of X65 steel are shown in Table 1 . Coupons with different dimensions were cut from a tube sample. Coupons with the dimensions of $20 \mathrm{~mm} \times 20 \mathrm{~mm} \times 3 \mathrm{~mm}$ were prepared for weight loss measurements and surface characterizations. Coupons with the dimensions of $10 \mathrm{~mm} \times 10 \mathrm{~mm} \times 3 \mathrm{~mm}$ were prepared for electrochemical measurements at the atmospheric pressure $(0.1 \mathrm{MPa})$. Coupons processed into the cylinder with a diameter of $6 \mathrm{~mm}$ and a length of $20 \mathrm{~mm}$ were prepared for electrochemical measurements in the high HP environments. An internal screw thread with a diameter of $1.5 \mathrm{~mm}$ and a length of $10 \mathrm{~mm}$ was machined at one end of the cylindrical coupon. The cylindrical coupon was screwed to the high-pressure device through this internal screw thread. The coupons for electrochemical measurements at the atmospheric pressure were encapsulated by epoxy resin after welding with copper wires. All the coupons were ground by $\mathrm{SiC}$ paper up to 1500 grit and then cleaned with ethanol.

The electrolyte solution used in the proposed experiment was the artificial seawater (3.5 wt $\% \mathrm{NaCl}$ solution). By using a high-pressure device, the HP experiments were conducted at $0.1 \mathrm{MPa}, 4 \mathrm{MPa}, 8 \mathrm{MPa}$, and $12 \mathrm{MPa}$ at room temperature, respectively.

\subsection{The High-Pressure Simulation}

The HP experiments were conducted by using a high-pressure device as shown in Fig. 1. The device was set up by the pressurizing system, the pressure vessel, the temperature control system, and the electrochemical system. The HP was changed by inputting different amounts of the electrolyte solution through a manual hydraulic press. The HP was the only variable during the experiment, while other parameters remained unchanged. Since the pressure vessel was filled with the electrolyte solution and then sealed tightly during the experiment, the dissolved oxygen (DO) content at different HPs could be considered to be the same as the DO content at atmospheric pressure.

\subsection{Electrochemical Measurements}

The corrosion behaviors of X65 steel in the $3.5 \mathrm{wt} \% \mathrm{NaCl}$ solution under different HPs were measured by an electrochemical

\begin{tabular}{llllllllllll}
\hline Alloy & $\mathrm{C}$ & $\mathrm{Si}$ & $\mathrm{Mn}$ & $\mathrm{Ni}$ & $\mathrm{Cr}$ & $\mathrm{Mo}$ & $\mathrm{Cu}$ & $\mathrm{V}$ & $\mathrm{Nb}$ & $\mathrm{P}$ & $\mathrm{S}$ \\
\hline X65 & 0.09 & 0.26 & 1.30 & 0.15 & 0.04 & 0.17 & 0.13 & 0.04 & 0.03 & 0.007 & 0.002 \\
\hline
\end{tabular}




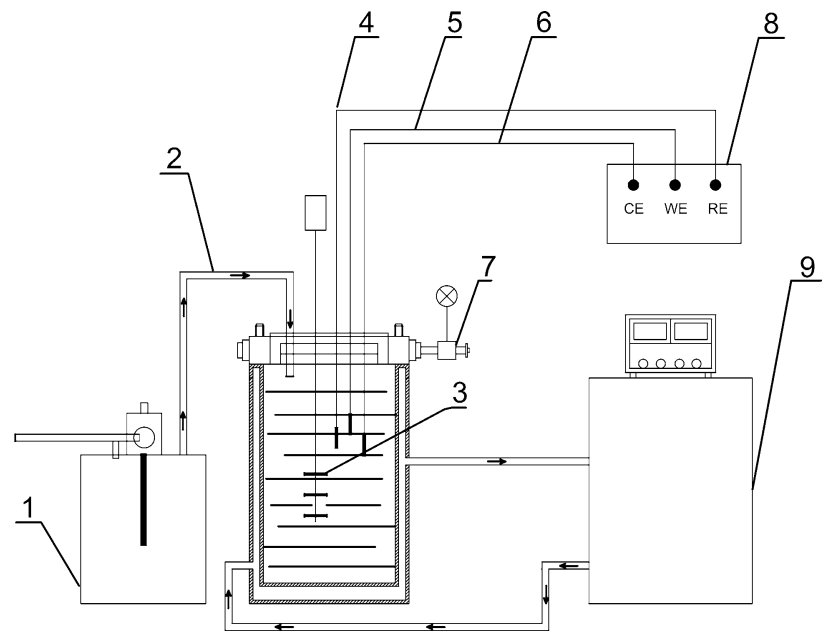

Fig. 1 Schematic diagram of the high-pressure device: (1) manual hydraulic press, (2) liquid inlet pipe, (3) hanging rod, (4) reference electrode, (5) working electrode, (6) counter electrode, (7) pressure gauge, (8) electrochemical workstation, (9) temperature controller

workstation (Autolab 302N, Metrohm, Switzerland) with a three-electrode system. The coupon of X65 steel was used as the working electrode (WE). $\mathrm{An} \mathrm{Ag} / \mathrm{AgCl}$ solid electrode was used as the reference electrode (RE), and a platinum wire served as the counter electrode (CE).

The potentiodynamic polarization measurements were taken after the X65 coupons had been immersed in the $3.5 \mathrm{wt} \% \mathrm{NaCl}$ solution for $10 \mathrm{~min}$. The scanning started from $-300 \mathrm{mV}$ versus the open-circuit potential (OCP) toward the anodic potential with a scanning rate of $1 \mathrm{mV} / \mathrm{s}$ until the current exceeded $1 \mathrm{~mA}$.

The electrochemical impedance spectroscopy (EIS) measurements were taken at $\mathrm{OCP}$, using a frequency range from $100 \mathrm{kHz}$ to $0.01 \mathrm{~Hz}$ and an amplitude of $10 \mathrm{mV}$. The data were fitted by ZSimpWin software after measurements.

\subsection{Surface Characterizations}

The X65 coupons were hanged and immersed in the beakers and the high-pressure device for the experiments at $0.1 \mathrm{MPa}$ and $12 \mathrm{MPa}$, respectively. After $14 \mathrm{~d}$ of immersion, the X65 coupons were taken out and rinsed with the distilled water. The corroded morphologies were observed by the scanning electron microscopy (SEM, S-4800, Hitachi, Japan) with an accelerating voltage of $5 \mathrm{kV}$.

The corrosion products formed on the X65 steel surface were analyzed by the X-ray diffraction instrument (XRD, D8 Advance, Bruker, Germany) with $\mathrm{Cu} K_{\alpha}$ as the X-ray source. The corrosion products were also investigated by the laser Raman spectrometer (Raman, inVia Reflex, RENISHAW, England) with a laser wavelength of $532 \mathrm{~nm}$. The expected
Table 2 The expected Raman peaks for iron oxide compounds

\begin{tabular}{llll}
\hline Compounds & Compositions & Raman shifts $\left(\mathrm{cm}^{-1}\right)$ & References \\
\hline Lepidocrocite & $\gamma-\mathrm{FeOOH}$ & $255,380,1307$ & {$[16,17]$} \\
Maghemite & $\gamma-\mathrm{Fe}_{2} \mathrm{O}_{3}$ & $358,499,678,710$ & {$[18]$} \\
Magnetite & $\mathrm{Fe}_{3} \mathrm{O}_{4}$ & $297,532,616,670,680$ & {$[16,17,19]$} \\
Goethite & $\alpha-\mathrm{FeOOH}_{2}$ & $390,485,554$ & {$[16,17]$} \\
Hematite & $\alpha-\mathrm{Fe}_{2} \mathrm{O}_{3}$ & $292,415,500,615$, & {$[17,19]$} \\
& & 1320 & \\
\hline
\end{tabular}

Raman peaks for various iron oxide compounds in the proposed experiment are shown in Table 2.

After the characterizations, the corrosion products on the coupon surface were removed. The coupons were then prepared for the weight loss measurements.

\subsection{Weight Loss Measurements}

The solution for removing the corrosion products consisted of (per liter of distilled water) hydrochloric acid $500 \mathrm{~mL}$ and hexamethylenetetramine $3.5 \mathrm{~g}$. After cleaned by this solution, the X65 coupons were rinsed with the distilled water, dried, and then weighed. The mass losses of the X65 coupons were measured by a high-accuracy mass balance with a precision of $0.0001 \mathrm{~g}$. The corrosion rates were calculated by the equation formulated as follows [20],

Corrosion Rate $\left(\mathrm{mm} \mathrm{y}^{-1}\right)=(K \times W) /(A \times T \times D)$,

where $K$ represents a constant equal to $8.76 \times 10^{4} ; W(\mathrm{~g})$ represents the mass loss; $A\left(\mathrm{~cm}^{2}\right)$ represents the area; $T(\mathrm{~h})$ represents the time of exposure; and $D\left(\mathrm{~g} \mathrm{~cm}^{-3}\right)$ represents the density of the X65 steel.

\section{Results}

\subsection{Potentiodynamic Polarization Results}

Figure 2 illustrates the potentiodynamic polarization curves for X65 steel exposed to the $3.5 \mathrm{wt} \% \mathrm{NaCl}$ solution at different pressures. As shown in Fig. 2, the anodic current density increases as the HP increases, indicating the anodic dissolution rate is enhanced by the HP. The oxygen reduction reaction is the cathodic reaction of $\mathrm{X} 65$ steel in the $3.5 \mathrm{wt} \% \mathrm{NaCl}$ solution at a neutral $\mathrm{pH}$. The cathodic region of the curves presents a platform, which means the oxygen reduction reaction at the cathode is under mass transport control. The limiting current densities $\left(i_{\mathrm{L}}\right)$ at the high HPs are larger than the $i_{\mathrm{L}}$ at the atmospheric pressure. The corrosion current density and the corrosion potential obtained from the curves are presented in Table 3. 


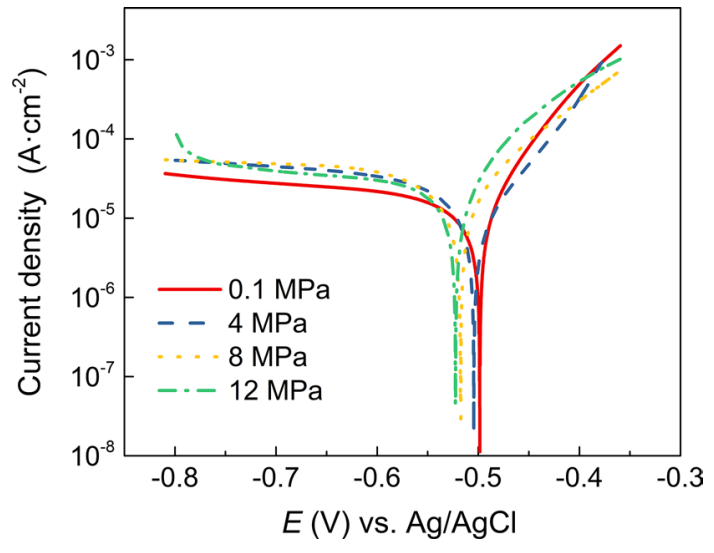

Fig. 2 Polarization curves for X65 steel exposed to the $3.5 \mathrm{wt} \% \mathrm{NaCl}$ solution at different pressures

Table 3 Evolutions of polarization parameters for X65 steel immersed in the $3.5 \mathrm{wt} \% \mathrm{NaCl}$ solution at different pressures

\begin{tabular}{lll}
\hline Pressure $(\mathrm{MPa})$ & \multicolumn{2}{l}{ Parameters } \\
\cline { 2 - 3 } & $I_{\text {corr }}\left(\mathrm{A} \mathrm{cm}^{-2}\right)$ & $E_{\text {corr }}(\mathrm{V})$ \\
\hline 0.1 & $1.748 \times 10^{-5}$ & -0.4986 \\
4 & $3.186 \times 10^{-5}$ & -0.5047 \\
8 & $3.778 \times 10^{-5}$ & -0.5175 \\
12 & $4.885 \times 10^{-5}$ & -0.5224 \\
\hline
\end{tabular}

\section{(a)}

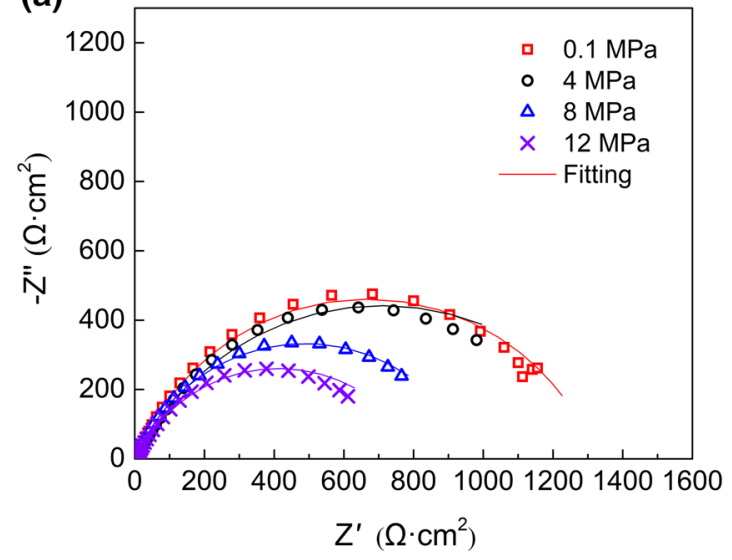

\subsection{EIS Results}

At OCP, EIS measurements were taken on the corrosion systems at different HPs. Figure 3 illustrates the impedance responses for X65 steel exposed to the $3.5 \mathrm{wt} \% \mathrm{NaCl}$ solution at different HPs. The Nyquist plots are shown in Fig. 3a, and the corresponding Bode plots are shown in Fig. 3b. As shown in Fig. 3a, at all the HPs, the Nyquist plots display one depressed semicircle at high and low frequencies. The diameter of the depressed semicircles decreases as the HP increases. At $12 \mathrm{MPa}$, the diameter reaches about half of the diameter at atmospheric pressure. The Bode plots also confirm the characteristic of one time constant, shown in Fig. 3b. The modulus decreases as the HP increases, indicating a reduction in the impedance of the corrosion system.

As demonstrated from the EIS results shown in Fig. 3, the impedance responses remain one time constant at each HP. To extract the electrochemical parameters at different HPs, an equivalent circuit is used to fit the EIS results, as shown in Fig. 4. In the equivalent circuit model, $Q$ represents the characteristic parameter of constant phase element (CPE). The impedance of CPE can be calculated by Eq. (2) [21],

$Z_{\mathrm{CPE}}=1 /(j \omega)^{\alpha} Q$,

where $\alpha$ is dispersion coefficient related to the heterogeneous condition of the electrode surface.

As shown in Fig. $4, R_{\mathrm{s}}$ is the solution resistance. $R_{\mathrm{p}}$ is the polarization resistance, and $Q_{\mathrm{dl}}$ is the double-layer

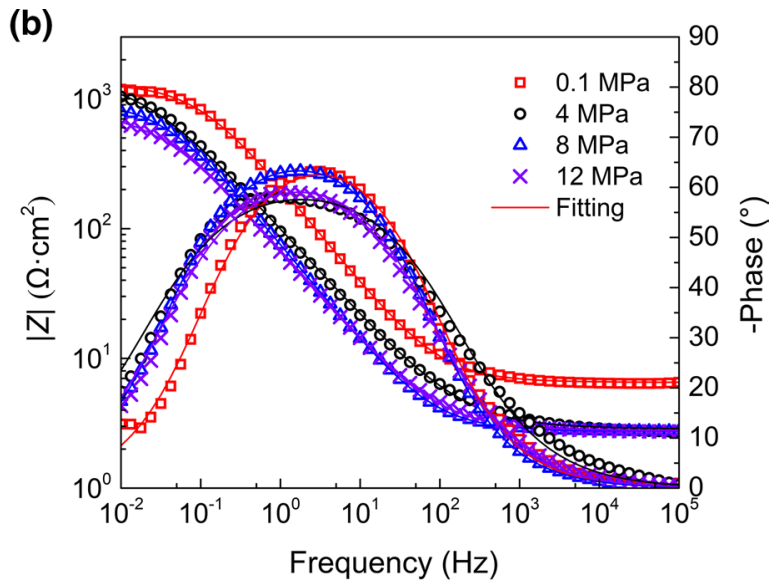

Fig. 3 Electrochemical impedance spectra for X65 steel exposed to the $3.5 \mathrm{wt} \% \mathrm{NaCl}$ solution at different pressures. a Nyquist plot, b Bode plots

As shown in Table 3 , the corrosion current density $\left(i_{\text {corr }}\right)$ increases as the HP increases. The corrosion potential $\left(E_{\text {corr }}\right)$ moves toward the negative as the pressure increases. The potentiodynamic polarization results indicate the corrosion of X65 steel in the artificial seawater is accelerated by the HP, and the corrosion rate increases with the HP.

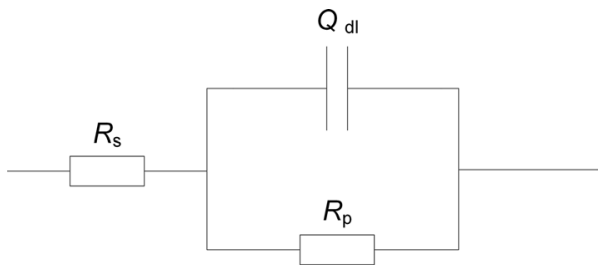

Fig. 4 The equivalent circuit model used for EIS fitting analysis 
Table 4 Evolutions of electrochemical impedance parameters for X65 steel immersed in the $3.5 \mathrm{wt} \% \mathrm{NaCl}$ solution at different pressures

\begin{tabular}{llllll}
\hline Pressure $(\mathrm{MPa})$ & \multicolumn{2}{l}{ Parameters } & & & \\
\cline { 2 - 6 } & $R_{\mathrm{s}}\left(\Omega \mathrm{cm}^{2}\right)$ & $\alpha$ & $Q_{\mathrm{dl}}\left(\mathrm{mF} \mathrm{cm}^{-2}\right)$ & $R_{\mathrm{p}}\left(\Omega \mathrm{cm}^{2}\right)$ & $\begin{array}{l}\text { Chi square } \\
\text { value } \\
\left(\times 10^{-3}\right)\end{array}$ \\
\hline 0.1 & 2.537 & 0.78 & 1.009 & 1319.0 & 1.140 \\
4 & 2.866 & 0.69 & 2.806 & 1237.0 & 2.633 \\
8 & 2.753 & 0.77 & 3.210 & 970.7 & 0.981 \\
12 & 2.776 & 0.72 & 3.824 & 819.4 & 0.790 \\
\hline
\end{tabular}

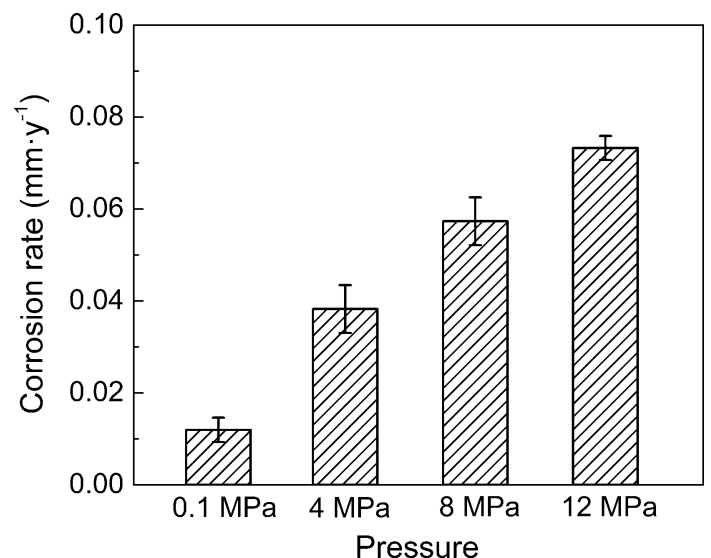

Fig. 5 Corrosion rates of X65 steel at different pressures in the $3.5 \mathrm{wt} \% \mathrm{NaCl}$ solution after 14 days of immersion

capacitance. The fitted results of parameters for different HPs are displayed in Table 4. As shown in Table 4, $R_{\mathrm{p}}$ decreases as the HP increases (from 1319.0 to 819.4 $\Omega \mathrm{cm}^{2}$ ), indicating the corrosion resistance of X65 steel is weakened by the increasing HP. $Q_{\mathrm{dl}}$ increases as the HP increases (from 1.009 to $3.824 \mathrm{mF} \mathrm{cm}^{-2}$ ). The increase in $Q_{\mathrm{dl}}$ can be caused by an increase in the surface roughness of WE or an increase in the porous corrosion products. Either of these two reasons can be induced by the accelerated corrosion. The trends of $R_{\mathrm{p}}$ and $Q_{\mathrm{dl}}$ are consistent with the potentiodynamic polarization results. The corrosion of X65 steel in the artificial seawater is accelerated by the HP.

\subsection{Weight Loss Results}

Figure 5 illustrates the corrosion rates of X65 steel at different HPs calculated by the weight loss. Since the results are obtained from the weight loss measurements after 14 days of immersion in the $3.5 \mathrm{wt} \% \mathrm{NaCl}$ solution, the corrosion rate is the average value during the whole experiment period. As shown in Fig. 5, the corrosion rates at the high HPs are larger than the rate at the atmospheric pressure. The corrosion rate increases as the HP increases. The corrosion rate trend is verified again by the weight loss data. The corrosion of X65 steel in the $3.5 \mathrm{wt} \% \mathrm{NaCl}$ solution is accelerated by the HP.

\subsection{Corroded Morphology Analysis}

Figure 6 illustrates the corroded morphologies of X65 steel exposed to the $3.5 \mathrm{wt} \% \mathrm{NaCl}$ solution at $0.1 \mathrm{MPa}$ and $12 \mathrm{MPa}$ for 14 days. As shown in Fig. 6a, at the atmospheric pressure, the corrosion products show a flaky morphology with cracks on the surface. The corroded morphology at $12 \mathrm{MPa}$ shows a morphology like an extruded topography, as shown in Fig. 6b. Wider and deeper cracks can be observed on the corrosion products layer. By comparing the surface
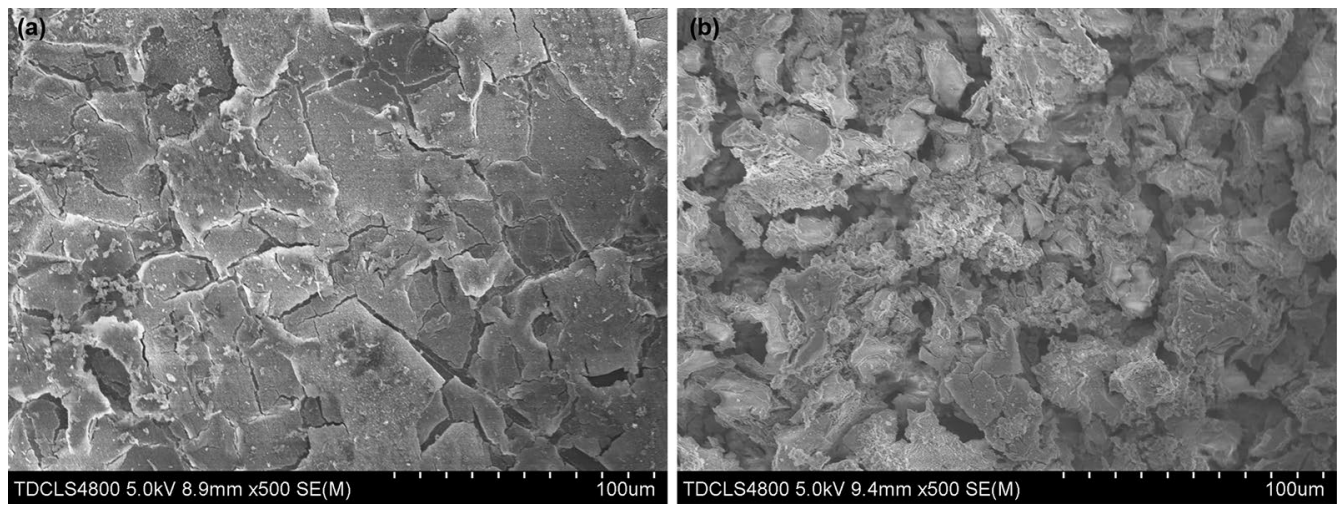

Fig. 6 Corroded morphologies of X65 steel exposed to the $3.5 \mathrm{wt} \% \mathrm{NaCl}$ solution at $0.1 \mathrm{MPa}$ a, $12 \mathrm{MPa} \mathbf{b}$ for 14 days 
morphologies of coupons immersed at different HPs, the high HP changes the distribution of the corrosion products on the surface of X65 steel.

\subsection{Corrosion Products Analysis}

Figure 7 illustrates the XRD spectra of the corrosion products obtained from the coupons after $14 \mathrm{~d}$ of immersion in the $3.5 \mathrm{wt} \% \mathrm{NaCl}$ solution at $0.1 \mathrm{MPa}$ and $12 \mathrm{MPa}$. As shown in Fig. $7 \mathrm{a}$, at the atmospheric pressure, the peaks can be picked up for two components, corresponding to $\gamma$-FeOOH and $\mathrm{Fe}_{3} \mathrm{O}_{4}$. The result indicates that the corrosion products obtained from the atmospheric pressure environment may mainly consist of $\gamma-\mathrm{FeOOH}$ and $\mathrm{Fe}_{3} \mathrm{O}_{4}$. As shown in Fig. 7b, at $12 \mathrm{MPa}, \gamma-\mathrm{FeOOH}, \mathrm{Fe}_{3} \mathrm{O}_{4}$, and $\gamma$ - $\mathrm{Fe}_{2} \mathrm{O}_{3}$ can be distinguished from the background noise. The result indicates that the corrosion products obtained from the high-pressure environment may mainly consist of $\gamma$-FeOOH, $\mathrm{Fe}_{3} \mathrm{O}_{4}$, and $\gamma-\mathrm{Fe}_{2} \mathrm{O}_{3}$.

To further understand and confirm the composition of the corrosion products at different pressures, Raman is utilized to analyze the corrosion products. Figure 8 illustrates the Raman spectra of the corrosion products obtained from the coupons after $14 \mathrm{~d}$ of immersion in the $3.5 \mathrm{wt} \% \mathrm{NaCl}$ solution at $0.1 \mathrm{MPa}$ and $12 \mathrm{MPa}$. As shown in Fig. 8a, at the atmospheric pressure, noticeable peaks are detected in the corrosion products. The peaks at 266,380 , and $1301 \mathrm{~cm}^{-1}$ are attributed to $\gamma$-FeOOH. The peak at $589 \mathrm{~cm}^{-1}$ suggests the presence of $\mathrm{Fe}_{3} \mathrm{O}_{4}$. At $12 \mathrm{MPa}$, as shown in Fig. 8b, new peaks are observed compared with the atmospheric condition. $\gamma-\mathrm{Fe}_{2} \mathrm{O}_{3}$ is responsible for the peaks at 364 and $390 \mathrm{~cm}^{-1} . \mathrm{Fe}_{3} \mathrm{O}_{4}$ is responsible for the peaks at 542, 598, and $683 \mathrm{~cm}^{-1}$. The peaks at 269 and $1302 \mathrm{~cm}^{-1}$ are attributed to $\gamma-\mathrm{FeOOH}$.
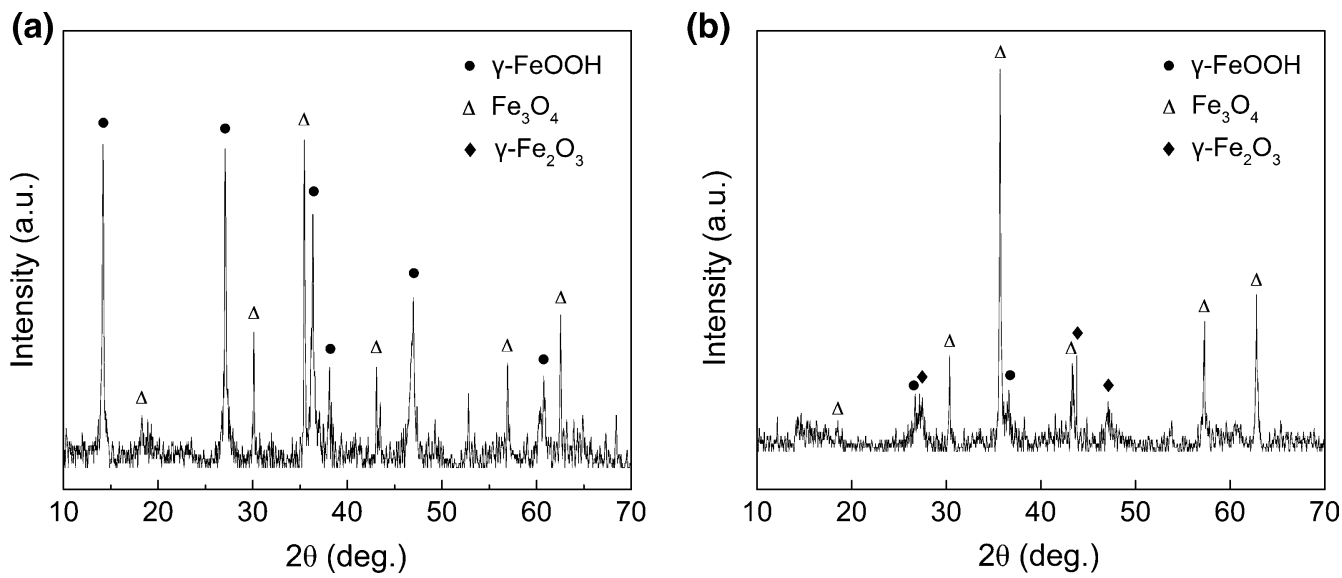

Fig. 7 XRD spectra of the corrosion products obtained from the samples after $14 \mathrm{~d}$ of immersion in the $3.5 \mathrm{wt} \% \mathrm{NaCl}$ solution at $0.1 \mathrm{MPa}$ a, $12 \mathrm{MPa} \mathbf{b}$
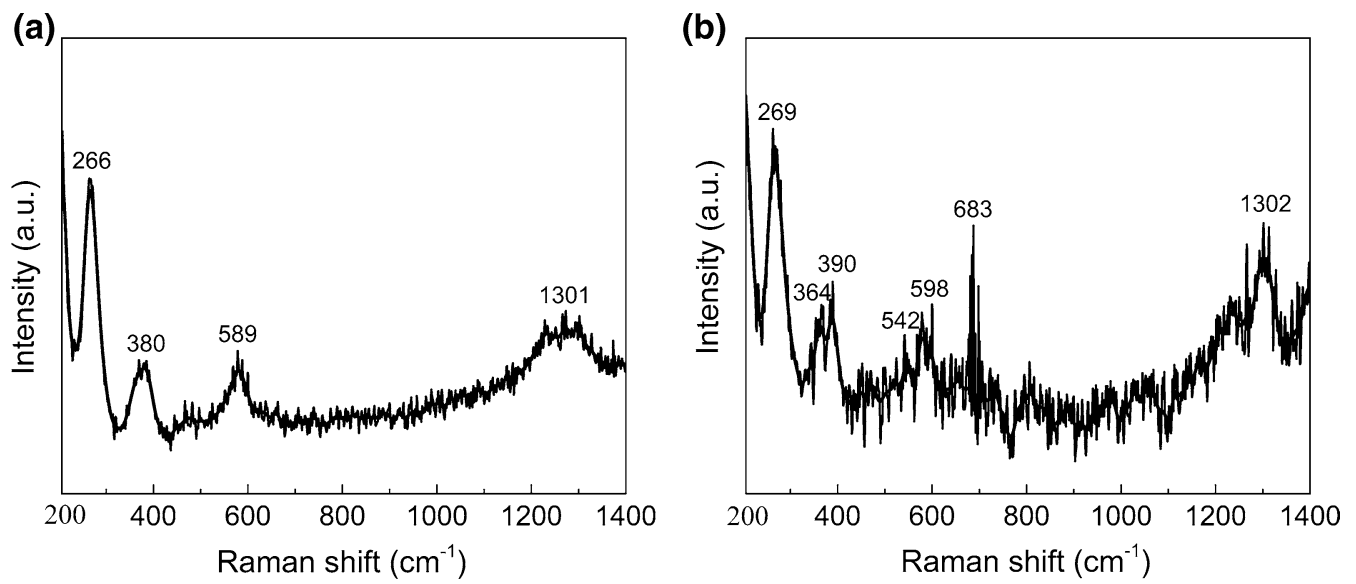

Fig. 8 Raman spectra of the corrosion products obtained from the samples after $14 \mathrm{~d}$ of immersion in the $3.5 \mathrm{wt} \% \mathrm{NaCl}$ solution at $0.1 \mathrm{MPa}$ a, $12 \mathrm{MPa} \mathbf{b}$ 
Through a comprehensive analysis of XRD and Raman, the corrosion products formed on X65 steel at the atmospheric pressure mainly consist of $\gamma-\mathrm{FeOOH}$ and $\mathrm{Fe}_{3} \mathrm{O}_{4}$. In the high-pressure environment, $\gamma-\mathrm{FeOOH}, \mathrm{Fe}_{3} \mathrm{O}_{4}$, and $\gamma-\mathrm{Fe}_{2} \mathrm{O}_{3}$ are the dominant phases in the corrosion products.

\section{Discussion}

The results above show that the HP influences the corrosion behavior of X65 steel during the immersion, including the corrosion rate, the distribution, and composition of corrosion products. For a deeper understanding of the influence mechanism, the discussion starts from the distinction of corrosion products at the two pressures (0.1 MPa and $12 \mathrm{MPa})$.

As shown in Figs. 7 and 8, the corrosion products mainly consist of $\gamma$-FeOOH and $\mathrm{Fe}_{3} \mathrm{O}_{4}$ at $0.1 \mathrm{MPa}$, and $\gamma-\mathrm{FeOOH}$, $\mathrm{Fe}_{3} \mathrm{O}_{4}$, and $\gamma-\mathrm{Fe}_{2} \mathrm{O}_{3}$ at $12 \mathrm{MPa}$. The macroscopic images of the corrosion products at the two pressures are presented in Fig. 9. The color of the products collected from the atmospheric pressure is russet, while the color is black at the high $\mathrm{HP}$ of $12 \mathrm{MPa}$. Due to these characteristic colors, it can be inferred that the dominant components are $\gamma-\mathrm{FeOOH}$ and $\mathrm{Fe}_{3} \mathrm{O}_{4}$ for $0.1 \mathrm{MPa}$ and $12 \mathrm{MPa}$, respectively. This inference is confirmed by the quantitative analysis of components in the corrosion products. Figure 10 illustrates the relative content of each component in the different corrosion products. As shown in Fig. 10, the amount of $\gamma-\mathrm{FeOOH}$ is much larger than $\mathrm{Fe}_{3} \mathrm{O}_{4}$ at $0.1 \mathrm{MPa}$, while at $12 \mathrm{MPa}$, the amount of $\mathrm{Fe}_{3} \mathrm{O}_{4}$ is nearly three times larger than the total amount of $\gamma-\mathrm{FeOOH}$ and $\gamma-\mathrm{Fe}_{2} \mathrm{O}_{3}$. The variation of relative content between the two pressures reveals that the HP has promoted the conversion from $\gamma$-FeOOH to $\mathrm{Fe}_{3} \mathrm{O}_{4}$ in the corrosion products.

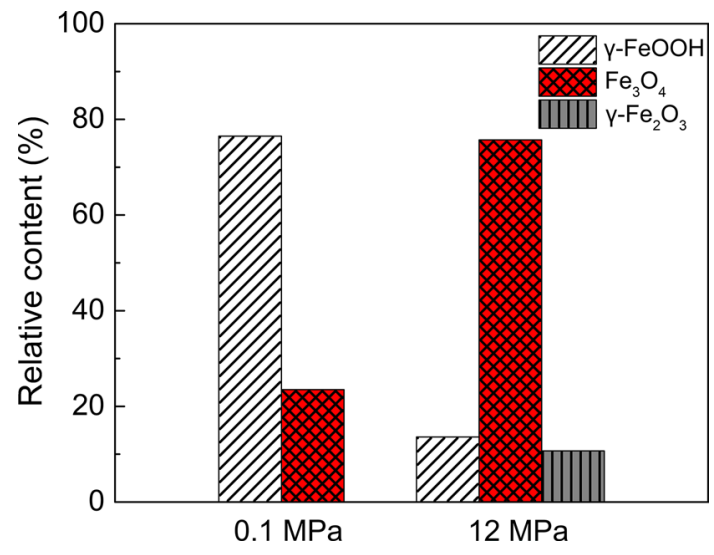

Fig. 10 The relative content of each component in the different corrosion products after $14 \mathrm{~d}$ of immersion in the $3.5 \mathrm{wt} \% \mathrm{NaCl}$ solution

The reduction of $\gamma-\mathrm{FeOOH}$ can be a cathodic reaction except the oxygen depolarization during the corrosion process of X65 steel with corrosion products. The reduction mechanism is proposed by Stratmann and Hoffmann [22]:

$3 \gamma-\mathrm{FeOOH}+\mathrm{H}^{+}+\mathrm{e}^{-} \rightarrow \mathrm{Fe}_{3} \mathrm{O}_{4}+2 \mathrm{H}_{2} \mathrm{O}$.

This reduction is influenced by the corrosion potential of steel. The reaction can only occur when the corrosion potential is below the reduction potential of $\gamma-\mathrm{FeOOH}$. Lair et al. [23] have reported that the reduction potential of $\gamma-\mathrm{FeOOH}$ is $-450 \mathrm{mV}$ (vs. SHE) in the $0.1 \mathrm{~mol} \mathrm{~L}^{-1}$ $\mathrm{NaCl}$ solution at $\mathrm{pH} 7.5$ and is $-510 \mathrm{mV}$ at $\mathrm{pH}$ 8.5. For the consideration of the $\mathrm{Ag} / \mathrm{AgCl}$ reference electrode used in this paper, the potentials are $-690 \mathrm{mV}$ and $-750 \mathrm{mV}$, respectively. Figure 11 illustrates the variation of $E_{\text {corr }}$ with time at $0.1 \mathrm{MPa}$ and $12 \mathrm{MPa}$. As shown in Fig. 11, $E_{\text {corr }}$ decreases with immersion time at both the two pressures.
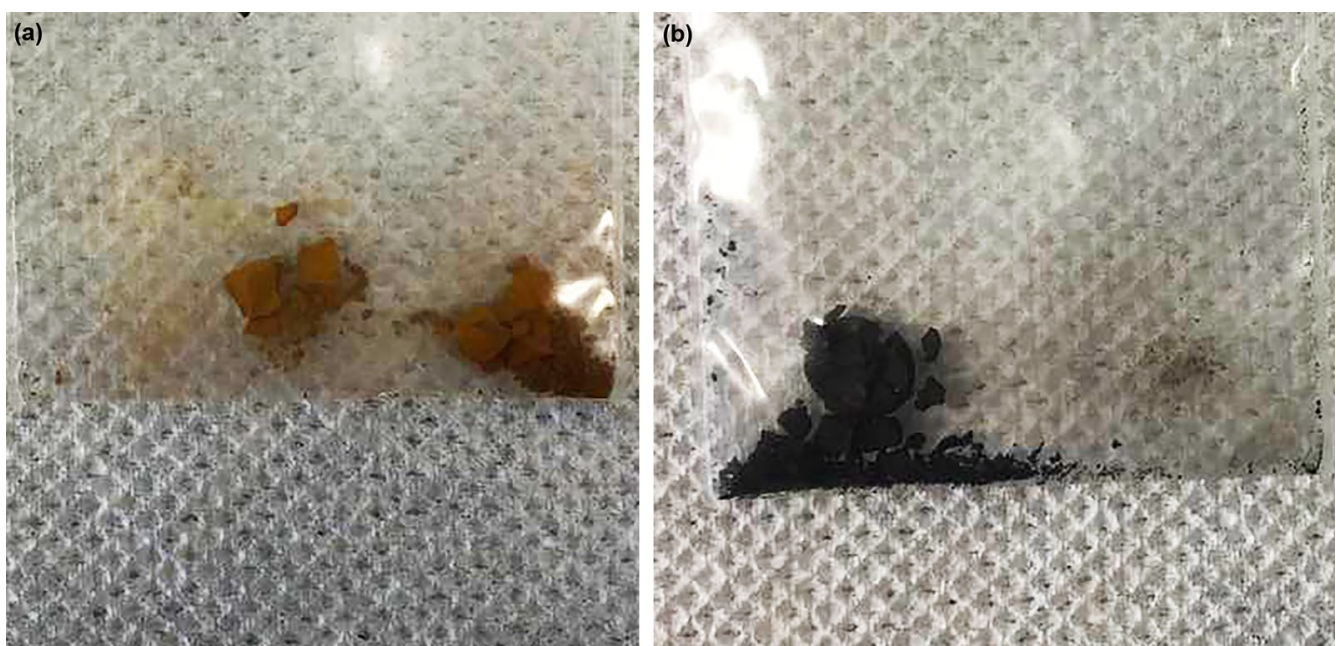

Fig. 9 Macroscopic images of the corrosion products after $14 \mathrm{~d}$ of immersion in the $3.5 \mathrm{wt} \% \mathrm{NaCl}$ solution at $0.1 \mathrm{MPa}$ a, $12 \mathrm{MPa}$ b 


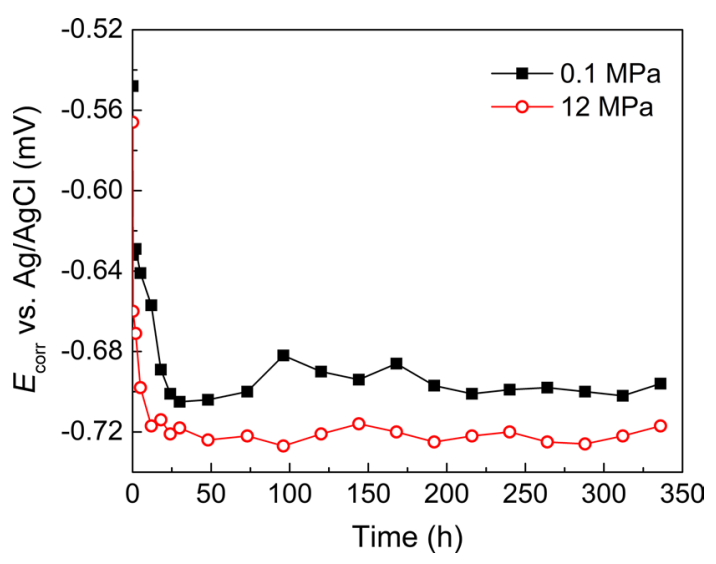

Fig. 11 Time dependence of $E_{\text {corr }}$ at $0.1 \mathrm{MPa}, 12 \mathrm{MPa}$

At the atmospheric pressure, the corrosion potential stabilizes at approximately $-700 \mathrm{mV}$ after $24 \mathrm{~h}$ of immersion. However, at $12 \mathrm{MPa}$, the corrosion potential reaches a steady state in a shorter time and presents a more negative potential at $-720 \mathrm{mV}$. The $\mathrm{pH}$ of the artificial seawater used in this experiment is neutral. Hence, the corrosion potentials at both the two pressures are lower than the reduction potential of $\gamma$-FeOOH, indicating the reduction of $\gamma$ - $\mathrm{FeOOH}$ can occur at the both pressures. Furthermore, the corrosion potential at $12 \mathrm{MPa}$ is lower than that at $0.1 \mathrm{MPa}$, which is more conducive to the reduction. The result is consistent with the increase in $\mathrm{Fe}_{3} \mathrm{O}_{4}$ relative content at $12 \mathrm{MPa}$ discussed above. The HP promotes the conversion from $\gamma-\mathrm{FeOOH}$ to $\mathrm{Fe}_{3} \mathrm{O}_{4}$ due to its effect on reducing the corrosion potential of X65 steel.

The reduction of $\gamma-\mathrm{FeOOH}$ at metal/rust interface can promote the cathodic reaction to accelerate the corrosion. The generated $\mathrm{Fe}_{3} \mathrm{O}_{4}$ has a good electrical conductivity, and oxygen can be reduced directly on its surface [24]. The corrosion can be accelerated due to the large cathode effect of the $\mathrm{Fe}_{3} \mathrm{O}_{4}$ layer. Meanwhile, as shown in Fig. 6, wider and deeper cracks can be observed on the corrosion products layer at $12 \mathrm{MPa}$. This change of cracks makes it easier for the corrosive species such as oxygen and $\mathrm{Cl}^{-}$transporting to the metal surface. Sun et al. have reported that higher content of $\mathrm{Cl}^{-}$is observed at the higher pressure than at $0.1 \mathrm{MPa}$. Deeper and larger cracks are also observed in the corrosion product layer [25]. The recent investigation conducted by Yang et al. has also confirmed the increase in the $\mathrm{Cl}^{-}$content. At $10 \mathrm{MPa}$, the content of $\mathrm{Cl}^{-}$in the corrosion products is more than twice higher than that at $0.1 \mathrm{MPa}$ [15]. The increased amount of corrosive species can enhance the environment corrosiveness, leading to the accelerated corrosion. In combination with the above reasons, including the promoted reduction of $\gamma-\mathrm{FeOOH}$ and the wider and deeper cracks on the corrosion products layer, the HP accelerates the corrosion of X65 steel in the artificial seawater.

\section{Conclusions}

1. The corrosion rate of $\mathrm{X} 65$ steel in the $3.5 \mathrm{wt} \% \mathrm{NaCl}$ solution increases as the HP increases. The increase in pressure leads to a decrease in $E_{\text {corr }}$ and $R_{\mathrm{p}}$.

2. The HP changes the distribution and the composition of the corrosion products on the surface of X65 steel. At the atmospheric pressure, the corrosion products show a flaky morphology with cracks on the surface. The corrosion products mainly consist of $\gamma$ - $\mathrm{FeOOH}$ and $\mathrm{Fe}_{3} \mathrm{O}_{4}$. At the high HP, the corrosion products show a morphology like an extruded topography and the cracks grow wider and deeper. $\gamma$ - $\mathrm{FeOOH}, \mathrm{Fe}_{3} \mathrm{O}_{4}$, and $\gamma$ - $\mathrm{Fe}_{2} \mathrm{O}_{3}$ are the dominant phases of the corrosion products.

3. The HP promotes the conversion from $\gamma-\mathrm{FeOOH}$ to $\mathrm{Fe}_{3} \mathrm{O}_{4}$ due to its effect on reducing the corrosion potential of X65 steel. The increase in corrosion rate is related to the changed chemical and physical properties of corrosion products layer affected by HP, including the promoted reduction of $\gamma-\mathrm{FeOOH}$ and the wider and deeper cracks on the corrosion products layer.

Acknowledgements This work was supported by National Basic Research Program of China (2014CB046801), National Natural Science Foundation of China (51471117), and Key Project of Tianjin Natural Science Foundation (13JCZDJC29500).

\section{References}

[1] Y. Yang, T. Zhang, Y. Shao, G. Meng, F. Wang, Corros. Sci. 52, $2697(2010)$

[2] P. Traverso, E. Canepa, Ocean Eng. 87, 10 (2014)

[3] Z. Yang, B. Kan, J. Li, Y. Su, L. Qiao, A.A. Volinsky, Materials 10, 1307 (2017)

[4] S.H. Xing, Y. Li, J.A. Wharton, W.J. Fan, G.Y. Liu, F. Zhang, X.D. Zhao, Mater. Corros. 68, 1123 (2017)

[5] R.E. Melchers, Corrosion 6, 895 (2005)

[6] F. Reinhart, J. Jenkins, Corrosion of Materials in Surface Seawater After 12 and 18 months of Exposure (Naval Civil Engineering Laboratory, Port Hueneme, 1972)

[7] R. Venkatesan, M.A. Venkatasamy, T.A. Bhaskaran, E.S. Dwarakadasa, M. Ravindran, Br. Corros. J. 37, 257 (2002)

[8] K. Ding, W. Guo, R. Qiu, J. Hou, L. Fan, L. Xu, J. Mater. Eng. Perform. 27, 4489 (2018)

[9] E. Canepa, R. Stifanese, L. Merotto, P. Traverso, Mar. Struct. 59, 271 (2018)

[10] A.M. Beccaria, G. Poggi, M. Arfelli, G. Maitogno, Corros. Sci. 34, 989 (1993)

[11] A.M. Beccaria, G. Poggi, G. Castello, Br. Corros. J. 30, 283 (1995)

[12] A.M. Beccaria, G. Poggi, D. Gingaud, P. Castello, Br. Corros. J. 29, 65 (1994)

[13] T. Zhang, Y. Yang, Y. Shao, G. Meng, F. Wang, Electrochim. Acta 54, 3915 (2009)

[14] C. Zhang, Z.W. Zhang, L. Liu, Electrochim. Acta 210, 401 (2016) 
[15] Z.X. Yang, B. Kan, J.X. Li, Y.J. Su, L.J. Qiao, J. Electroanal. Chem. 822, 123 (2018)

[16] J. Dünnwald, A. Otto, Corros. Sci. 29, 1167 (1989)

[17] M.B. Leban, T. Kosec, Eng. Fail. Anal. 79, 940 (2017)

[18] M. Hanesch, Geophys. J. Int. 177, 941 (2009)

[19] O.N. Shebanov, P. Lazor, J. Raman Spectrosc. 34, 845 (2003)

[20] ASTM G1-03, Standard Practice for Preparing, Cleaning, and Evaluating Corrosion Test Specimens. (ASTM International, West Conshohocken, 2003)
[21] M.E. Orazem, B. Tribollet, Electrochemical Impedance Spectroscopy (Wiley, Hoboken, 2008)

[22] M. Stratmann, K. Hoffmann, Corros. Sci. 29, 1329 (1989)

[23] V. Lair, H. Antony, L. Legrand, A. Chausse, Corros. Sci. 48, 2050 (2006)

[24] U.R. Evan, Nature 206, 980 (1965)

[25] H. Sun, L. Liu, Y. Li, F. Wang, J. Electrochem. Soc. 160, C89 (2013) 